\title{
Losers Win, Winners Lose: Evidence against Market Efficiency
}

\author{
Zachary Alexander Smith ${ }^{1}$ \\ ${ }^{1}$ Donald R. Tapia School of Business, Saint Leo University, Saint Leo, USA \\ Correspondence: Zachary Alexander Smith, Donald R. Tapia School of Business, Saint Leo University, Saint Leo, \\ FL. 33574-6665, USA. Tel: 757-202-8914. E-mail: zachary.smith@saintleo.edu
}

Received: January 12, 2015

Accepted: January 28, 2015

Online Published: March 9, 2015

doi:10.5430/ijfr.v6n2p1

URL: http://dx.doi.org/10.5430/ijfr.v6n2p1

\begin{abstract}
The goal of this research project was to evaluate whether there is statistically significant evidence of the Winner / Loser Phenomenon identified in DeBondt and Thaler (1985) using a unique data set and multiple examination windows. This study finds statistically significant evidence of short-run negative autocorrelation of returns. More importantly, if investors used a daily rebalance over this time period and invested simultaneously in the previous day's loser ETF and the previous day's winner ETF they would have obtained Cumulative Abnormal Returns of $113.50 \%$ and $-134.13 \%$, respectively. In addition, this study supports the experimental research findings documented in Bloomfield, R., Libby, R., and Nelson, M. (1998) and Bloomfield, R. and Hales, J. (2002) by providing evidence that (a) the performance of the market portfolio and the loser portfolio show signs of trending behavior and (b) the loser portfolio shows signs of significant outperformance conditioned upon a negative performance event.
\end{abstract}

Keywords: winner / loser hypothesis, negative autocorrelation, abnormal performance

\section{Introduction}

In a seminal article in the field of behavioral finance, De Bondt, W. and Thaler, R. (1985) found that an investment in a portfolio constructed of 'Losing Stocks' (i.e. bottom decile performers) using a trailing 36-month estimation window outperformed a portfolio constructed of 'Winning Stocks' (i.e. top decile performers) over a three year period following the portfolio's formulation. De Bondt et al. examined the sample period that lasted from 1933 to 1980 and found that over a 36-month period the Loser Portfolios outperformed the Winning Portfolios by $24.6 \%$ using the Cumulative Abnormal Return (CAR) Methodology. De Bondt et al. further illustrated that over the 1, 13, and 25 month periods the CARs for the Losers over the Winners was $8.1 \%, 5.6 \%$, and $4.0 \%$, respectively. However, the researchers concluded that the majority of the excess returns were generated in January and subsequent papers (e.g. Jegadeesh, 1989) have argued that the abnormal performance found in DeBondt et al. was presumably due to turn-of-the-year and seasonality affects.

Expanding the work laid out by DeBondt and Thaler (1985), Jegadeesh, N. (1989) found evidence of negative serial autocorrelation, when analyzing portfolios constructed of individual securities decile ranked by their preceding one-month returns, the sample period ran from 1934 to 1987. Jegadeesh, N. (1989) also concluded that when longer-term time horizons are used, there is evidence of positive longer-term autocorrelation. Indicating that, in the short-term, we should expect trends to mean revert and in the longer-term we should expect persistence in the trend. Jegadeesh, N. and Titman, S. (1993) found evidence, using a time horizon including the period lasting from 1965 to 1989, that a strategy of selecting stocks based on their preceding 6-month returns, buying the 'Winners' and selling the 'Losers', and holding these individual securities for six-months generated an abnormal performance of $12.01 \%$ (p. 89). This finding provides somewhat contradictory evidence of the initial finding presented in DeBondt et al. Combining the results of these two studies, it seems as though the length of the event and estimation periods will influence the conclusions of the research project and that researchers could posed two separate fundamental hypotheses: (a) Is there evidence of overreaction in the short-term performance (i.e. is there statistically significant evidence of negative serial auto-correlation) and (b) Is there evidence of longer-term persistence in trends (i.e. can researchers find longer-term positive autocorrelation).

The purpose of this study is to examine whether there is evidence of short-term negative autocorrelation in securities prices (Note 1). The researcher will use the result presented in DeBondt and Thaler (1985) as a platform to explore whether the 'Loser Portfolio Effect' is more pronounced than the researchers surmised and whether a simple trading 
strategy could be constructed to exploit this tendency. This paper adds to the current body of literature by: (a) Using a unique data set to explore 'Winner' / 'Loser' behavior, (b) Allowing the portfolio formulation starting point to vary (this would minimize the 'January Effect' and concerns about 'Seasonality'), and (c) Tests whether this Winner / Loser Effect is evident over different sample time horizons (i.e. pre-crisis, crisis, and post-crisis periods $\mid$ crisis refers to the financial collapse of 2008) using different units of measurement (i.e. daily, weekly, and monthly rebalancing). The results are compelling and the evidence presented in this research project suggests that Debondt and Thaler's (1985) 'Winner / Loser' Phenomenon is more pronounce using a short-term time horizon.

\section{Material and Methods}

The data used in this analysis was obtained from Yahoo! Finance. The researcher gathered daily, weekly, and monthly time series data on the following ETFs: (a) VCR: Consumer Discretionary, (b) VDC: Consumer Staples, (c) VDE: Energy, (d) VFH: Financials, (e) VHT: Healthcare, (f) VIS: Industrials, (g) VGT: Information Technology, (f) VAW: Materials, (g) VNQ: REITS, (h) VOX: Telecommunications, and (i) VPU: Utilities. The time horizon of this study ranged from January 10, 2005 to April 7, 2014 (January 10, 2005 was the earliest relative start date for all of the ETFs analyzed in this paper); therefore, there were 2,403 daily, 482 weekly, and 110 monthly observations.

To construct the 'Winner' and 'Loser' Portfolios the researcher obtained price series data for the 11 Vanguard Sector ETFs used in this analysis from Yahoo!Finance. The return series were generated by calculating the daily, weekly, and monthly returns for each ETF using the holding period return calculation:

$$
H P R_{i, t}=\left(P_{t}-P_{t-1}\right) / P_{t-1}
$$

The previous daily, weekly, and monthly ETF's returns were then ranked from 1 to 11 in terms of their performance relative to the other Sector ETFs during that time period. The 'Loser Portfolio' was $100 \%$ invested in the preceding week's worst performing sector and the 'Winner Portfolio' was 100\% invested in the preceding week's best performing sector. Once a day, week, and month elapsed, the researcher rebalanced the portfolio and invested in the previous day, week, and month's Winner and Loser Portfolios.

According to Campbell, J. Lo, A., and MacKinlay, A. (1997), the cumulative abnormal return of a strategy can be estimated against an index as follows:

$$
\overline{C A R}\left(\tau_{1}, \tau_{2}\right)=\frac{1}{n} \sum_{i=1}^{N} \overline{C A R}_{i}\left(\tau_{1}, \tau_{2}\right)
$$

Campbell, J. Lo, A., and MacKinlay, A. (1997) stated that the variance of the CAR can be estimated as follows:

$$
\operatorname{Var}\left(\overline{C A R}\left(\tau_{1}, \tau_{2}\right)\right)=\frac{1}{N^{2}} \sum_{i=1}^{N} \sigma_{1}^{2}\left(\tau_{1}, \tau_{2}\right)
$$

Campbell et al. (1997) concluded that a hypothesis test, carried out to determine if the CAR is statistically different from zero, can be carried out using the following test:

$$
j_{1}=\frac{\overline{C A R}\left(\tau_{1}, \tau_{2}\right)}{\left(\widehat{\bar{\sigma}}^{2}\left(\tau_{1}, \tau_{2}\right)\right)^{1 / 2}} \sim \mathcal{N}(0,1)
$$

Researchers have questioned whether the 'Winner' / ' Loser' phenomenon found in DeBondt and Thaler (1985) can be explained by asserting that the 'Winner' / 'Loser' Portfolios simply take on more systemic risk; therefore, the anomaly (i.e. outperformance by the Loser and underperformance by the Winner) can be explained by examining each strategy's systemic risk. Estimates of systemic risk can be ascertained, according to Ang, A., Chen, J., and Xing, Y. (2006), by calculating the upside and downside betas. The upside beta can be calculated as follows:

$$
\beta^{+}=\frac{\operatorname{cov}\left(r_{i}, r_{m} \mid r_{m}<\mu_{m}\right)}{\operatorname{var}\left(r_{m} \mid r_{m}<\mu_{m}\right)}
$$

In addition, as stated in Ang, A., Chen, J., and Xing, Y. (2006), the downside beta can be calculated as follows:

$$
\beta^{-}=\frac{\operatorname{cov}\left(r_{i}, r_{m} \mid r_{m}>\mu_{m}\right)}{\operatorname{var}\left(r_{m} \mid r_{m}>\mu_{m}\right)}
$$

To calculate the upside and downside betas of the portfolio, the researcher calculated the average performance of the equally weighted index returns. The portfolios returns were ranked and the returns on the portfolio that were above the average return were included in the positive return cohort and the returns that fell below the average return were included in the negative return cohort. The Equally Weighted returns in each cohort were paired through time with the returns for the indiviudal ETFs as well as the Winner and Loser Portfolios. Finally, the upside and downside betas were calculated. 


\section{Results and Discussion}

The results presented in Table 1, indicate that the evidence of an anomaly similar to the one presented in DeBondt and Thaler (1985) is most pronounced using daily rebalancing. Therefore, for the remainder of this study the researcher will focus in on the data obtained using a daily rebalance. To provide the reader with an understanding of the absolute levels of performance of the 'Equal Weight', 'Loser', and 'Winner' Portfolios, the researcher will report the performance for the (a) Entire Period, (b) Pre-Crisis Period, (c) Crisis Period, and (d) Post-Crisis Period using a daily rebalance. Over the entire period, the Cumulative Returns were $112.13 \%, 225.63 \%$, and $-22.00 \%$ for the 'Benchmark', 'Loser Portfolio', and 'Winner Portfolio'. During the Pre-Crisis Period, from October 1, 2004 to April 17, 2014, the Cumulative Returns were $37.82 \%, 41.10 \%$, and $18.14 \%$, respectively. During the crisis, from September 22, 2008 until March 9, 2009, the Cumulative Returns for the portfolios were $-54.81 \%, 3.03 \%$, and $-118.31 \%$, respectively. During the post-crisis period, lasting from 3/10/2009 to 4/17/2014, the Cumulative Returns were $129.11 \%, 181.49 \%$, and $78.17 \%$, respectively.

Table 1. Cumulative abnormal return calculation for winner and loser portfolios

\begin{tabular}{lcc}
\hline Description & Winners & Losers \\
\hline Daily Rebalance & & \\
$\quad$ Total Sample & $-134.13 \%^{* * *}$ & $113.50 \%^{* *}$ \\
Pre-Crisis & $-19.68 \%$ & $3.28 \%$ \\
Crisis & $-63.50 \%^{* *}$ & $57.85 \%^{\wedge}$ \\
Post-Crisis & $-50.95^{\wedge}$ & $52.38 \%^{\wedge}$ \\
Weekly Rebalance & & \\
Total Sample & $25.20 \%$ & $109.61 \%^{* *}$ \\
Pre-Crisis & $31.92 \%$ & $32.14 \%$ \\
Crisis & $-6.48 \%$ & $16.72 \%$ \\
Post-Crisis & $-0.23 \%$ & $60.75 \%^{*}$ \\
Monthly Rebalance & & \\
Total Sample & -46.42 & $-98.21^{* *}$ \\
Pre-Crisis & -12.15 & $-74.85 \% * * *$ \\
Crisis & $-18.21 \%$ & $-9.24 \%$ \\
Post-Crisis & $-16.07 \%$ & $-14.1 \%^{*} \%$
\end{tabular}

Table 1 presents the results of this project's analysis of abnormal returns experienced in the strategies evaluated in this study. The researcher used the Cumulative Abnormal Return (CAR) procedure evaluated in Campbell, J. Lo, A., and MacKinlay, A. (1997) to determine if the 'average CAR' was significantly different from the Index (i.e. Equally Weighted ETF Sector Performance). The following indicators represent the $\alpha$ used to test whether the CAR was statistically different from zero $\left(\left.\left.\left.* * * .01\right|^{* *} .02\right|^{*} .05\right|^{\wedge} .10\right)$. The sample sizes for the Total Sample, Pre-Crisis, Crisis, and Post-Crisis periods were: (a) 2,403,1,000,116, and 1,287, respectively using a daily rebalance, (b) 482, 193, 23, and 266 , respectively using a weekly rebalance, and (c) $110,43,6$, and 61 , respectively using a monthly rebalance.

Table 2 provides the Betas, Average Performance, and Standard Deviation for all of the Sector ETFs as well as Winner, Loser, and Equally Weighted Portfolios included in this analysis using the entire sample of data. The Table, with a few exceptions, seems to indicate that the Loser Strategy is biased, in that it is more likely to select ETFs that have a higher beta. This could provoke readers to assume that the outperformance can be explained by stating that the outperformance occurs because the strategy takes on more systematic risk than the Winner and Equally Weighted Portfolios. The results that are particularly interesting are those contained in the 'crisis period' for this sample. The 'Loser Portfolio' takes on additional risk during a period in which the market proxy experiences negative performance and additional risk leads to positive returns. 
Table 2. Descriptive statistics for ETFs

\begin{tabular}{lccccccccc}
\hline & \multicolumn{3}{c}{ Post-Crisis } & \multicolumn{3}{c}{ Crisis } & \multicolumn{3}{c}{ Pre-Crisis } \\
\hline Portfolio & $\beta$ & $\mu$ & $\sigma$ & $\beta$ & $\mu$ & $\sigma$ & $\beta$ & $\mu$ & $\sigma$ \\
\hline Equal Weight & 1.00 & $0.10 \%$ & $1.18 \%$ & 0.99 & $-0.47 \%$ & $3.73 \%$ & 1.00 & $0.04 \%$ & $0.94 \%$ \\
Loser & 1.18 & $0.14 \%$ & $1.63 \%$ & 1.24 & $0.03 \%$ & $5.33 \%$ & 1.15 & $0.04 \%$ & $1.47 \%$ \\
Winner & 1.00 & $0.06 \%$ & $1.44 \%$ & 1.03 & $-1.02 \%$ & $4.57 \%$ & 1.06 & $0.02 \%$ & $1.37 \%$ \\
VCR & 1.04 & $0.13 \%$ & $1.30 \%$ & 0.94 & $-0.51 \%$ & $3.63 \%$ & 1.02 & $0.01 \%$ & $1.10 \%$ \\
VDC & 0.56 & $0.08 \%$ & $0.78 \%$ & 0.58 & $-0.30 \%$ & $2.36 \%$ & 0.59 & $0.04 \%$ & $0.68 \%$ \\
VDE & 1.16 & $0.09 \%$ & $1.52 \%$ & 1.28 & $-0.40 \%$ & $5.27 \%$ & 1.07 & $0.09 \%$ & $1.64 \%$ \\
VFH & 1.41 & $0.12 \%$ & $1.82 \%$ & 1.30 & $-0.81 \%$ & $5.44 \%$ & 1.39 & $0.01 \%$ & $1.53 \%$ \\
VHT & 0.69 & $0.09 \%$ & $0.98 \%$ & 0.68 & $-0.28 \%$ & $2.79 \%$ & 0.65 & $0.02 \%$ & $0.79 \%$ \\
VIS & 1.14 & $0.12 \%$ & $1.41 \%$ & 0.93 & $-0.62 \%$ & $3.61 \%$ & 1.02 & $0.03 \%$ & $1.04 \%$ \\
VGT & 0.94 & $0.10 \%$ & $1.23 \%$ & 0.86 & $-0.39 \%$ & $3.38 \%$ & 0.99 & $0.03 \%$ & $1.11 \%$ \\
VAW & 1.20 & $0.10 \%$ & $1.53 \%$ & 1.09 & $-0.58 \%$ & $4.32 \%$ & 1.20 & $0.05 \%$ & $1.36 \%$ \\
VNQ & 1.43 & $0.13 \%$ & $1.97 \%$ & 1.58 & $-0.69 \%$ & $6.72 \%$ & 1.35 & $0.06 \%$ & $1.56 \%$ \\
VOX & 0.81 & $0.08 \%$ & $1.09 \%$ & 0.93 & $-0.31 \%$ & $3.76 \%$ & 0.94 & $0.03 \%$ & $1.06 \%$ \\
VPU & 0.60 & $0.07 \%$ & $0.91 \%$ & 0.74 & $-0.32 \%$ & $3.17 \%$ & 0.77 & $0.05 \%$ & $0.98 \%$ \\
\hline
\end{tabular}

Table 2 presents some descriptive statistics and financial metrics. The Beta of each ETF is calculated as the covariance of the individual ETFs and the average performance of all ETFs divided by the variance of the average performance of all ETFs over the entire sample period. The periods are defined as follows: (a) Pre-Crisis Period, from 10/1/2004 to 9/19/2008, (b) Crisis Period from 9/22/2008 until 3/9/2009, and (c) Post-Crisis Period lasting from 3/10/2009 to 4/17/2014. The analysis was run using a daily rebalance.

Figure 1 presents a risk / return plot for all of the ETFs used in this analysis as well as a plot for the 'Equally Weighted', 'Winner', and 'Loser' Portfolios. By inspecting the risk / return plot, it is evident that the systematic risk component does not entirely explain the abnormal performance. The VDE ETF or the Energy Sector generated the highest average return obtained through an investment in ETFs by taking on approximately the same risk that is inherent in an investment in the 'Loser' Portfolio. On a risk adjusted basis the Energy Sector produces 6.5 basis points of return and assumes 192.3 basis points of risk compared to 9.39 basis points of return for 192 basis points of risk. That is a $144.46 \%$ increase in return by taking on the same level of risk. On the other hand, the closet comparable for the 'Loser' Portfolio from a risk perspective is VAW or the Materials ETF. The 'Winner' Portfolio obtains on average 6 basis points less return on a daily basis and takes on approximately the same level of risk.

Table 3 provides the Upside and Downside Betas and the number of times that the each of the Sector ETFs were included in the Winner and Loser Portfolios. To provide an indication that the value of the selection process in the Winner and Loser Portfolios is not generated primarily through the selection of ETFs that offer low / high systemic risk or higher upside / downside capture ratios, the researcher calculated the number of times the strategy selected the firms with high upside / downside capture ratios and low upside / downside capture ratios. Interestingly enough, the number of times that the 4 best sector ETFs, based upon the upside / downside capture ratios, were selected for inclusion to the Winner and Loser Portfolios were 852 and 891 times respectively over the entire sample period. Whereas the number of times the 4 worst sector ETFs, based upon the ratio of upside to downside capture ratios, were selected for inclusion to the Winner and Loser Portfolios were 1,081 and 1,004 times respectively over the entire sample period. This analysis indicates that the 'selection process' does not seem to favor ETFs that have higher upside / downside capture ratios. 


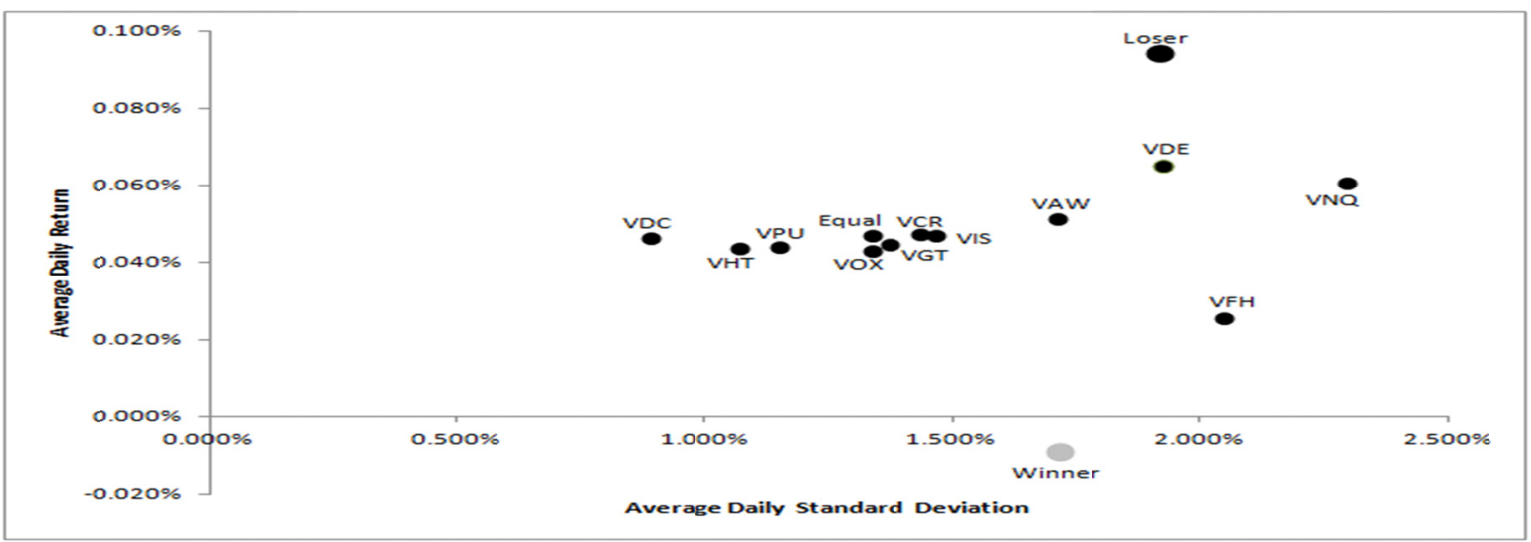

Figure 1. Risk / return plot for all ETFs and winner / loser portfolios

Figure 1 presents a plot of the risk / return characteristics of the performance of all ETFs, The Equally Weighted Portfolio, The Winner Portfolio, and the Loser Portfolio rebalanced daily using the entire sample, which was run from January 10, 2005 to April 7, 2014. The sample return and standard deviation statistics were estimated using the daily return across the entire sample.

To make sure that these results were not presented out of context, the researcher ran the same analysis on the Pre-Crisis, Crisis, and Post-Crisis Periods. The Tables that illustrate the upside and downside beta capture as well as the ratio between the two have been excluded for brevity. During the Pre-Crisis period the ETFs that were selected for inclusion in the Winner and Loser Portfolios that had the highest beta ratio (i.e. $\beta+/ \beta$-) were 323 and 392, respectively, and the ETFs that had the lowest beta ratio were selected 553 and 461 times, respectively. During the Crisis period the number of times that the ETFs with the highest beta ratio that were selected for inclusion in these strategies were 31 and 25 , respectively, and for the ETFs that had the lowest beta ratio were 63 and 73 times, respectively. During the Post-Crisis Period the number of times that the ETFs with the highest beta ratio where selected for inclusion in the Winner and Loser Portfolios were 498 and 474, respectively, and the number of times that the ETFs that had the lowest betas that were selected for inclusion in the portfolios were 465 and 470 times, respectively. Given the results of the preceding analysis, it does not seem reasonable or warranted to conclude that the finding that the Loser Portfolios outperformed and the Winner Portfolios underperformed the Equally Weighted Portfolio was due to systematic risk factors.

Table 3. Upside / downside beta comparison for ETFs (Entire sample)

\begin{tabular}{cccccc}
\hline Variable & $\beta_{+}$ & $\beta_{-}$ & $\beta_{+} / \beta_{-}$ & $n_{W}$ & $n_{L}$ \\
\hline VNQ & 1.61 & 1.46 & $110.44 \%$ & 375 & 372 \\
VFH & 1.46 & 1.37 & $106.96 \%$ & 188 & 209 \\
VOX & 0.92 & 0.89 & $103.46 \%$ & 104 & 102 \\
VGT & 0.92 & 0.89 & $103.26 \%$ & 185 & 208 \\
VCR & 0.99 & 0.98 & $101.18 \%$ & 126 & 141 \\
VPU & 0.69 & 0.69 & $100.05 \%$ & 149 & 154 \\
VIS & 1.00 & 1.04 & $96.76 \%$ & 195 & 211 \\
VHT & 0.65 & 0.67 & $96.61 \%$ & 245 & 257 \\
VDC & 0.55 & 0.58 & $95.21 \%$ & 241 & 203 \\
VDE & 1.14 & 1.25 & $91.31 \%$ & 201 & 216 \\
VAW & 1.06 & 1.19 & $89.42 \%$ & 394 & 328 \\
\hline
\end{tabular}

Table 3 summarizes the upside and downside betas for each of the sector ETFs included in this analysis, the upside / downside ratio, which is the upside beta divided by the downside beta, and the number of times that the individual ETF was selected for inclusion in the Winner and Loser Portfolios. The entire sample period was run from September 30, 2004 to April 7, 2014. 
Table 4 presents a comparison of the Upside and Downside Betas using the Equally-Weighted, Loser, and Winner Portfolios over the three different sample periods. A cursory review of Table 4 presents evidence that the selection process of the strategy (i.e. investing in the Loser ETF Portfolio over the Winner) generates higher risk adjusted and absolute returns over each of the sample time horizons using a daily rebalance. Furthermore, the Winner Portfolio consistently underperforms the Equally-Weighted Index on a risk adjusted basis and the Loser Portfolio consistently outperforms the Equally-Weighted Index on a risk adjusted basis.

Table 4. Upside / downside beta comparison

\begin{tabular}{lccccccccc}
\hline & \multicolumn{3}{c}{ Downside Beta } & \multicolumn{3}{c}{ Upside Beta } & \multicolumn{2}{c}{ Upside Beta / Downside Beta } \\
\hline Time Period & EW & L & W & EW & L & W & EW & L & W \\
\hline Total Sample & 1.00 & 1.07 & 1.10 & 1.00 & 1.36 & 0.94 & $100 \%$ & $128 \%$ & $85 \%$ \\
Pre-Crisis & 1.00 & 1.05 & 1.09 & 1.00 & 1.15 & 1.03 & $100 \%$ & $109 \%$ & $95 \%$ \\
Crisis & 0.98 & 1.16 & 1.00 & 0.98 & 1.21 & 0.87 & $100 \%$ & $104 \%$ & $87 \%$ \\
Post-Crisis & 1.00 & 1.01 & 1.03 & 1.00 & 1.36 & 0.94 & $100 \%$ & $135 \%$ & $91 \%$ \\
\hline
\end{tabular}

Table 4 provides estimates of the Upside and Downside Betas for the Equal Weighted Portfolio (EW), Loser Portfolio (L), and Winner (W). The Winner Portfolio and the Loser Portfolio are rebalanced daily using the entire sample, which was run from September 30, 2004 to April 7, 2014. The sample return and standard deviation statistics were estimated using the daily return across the entire sample. B. is calculated by identifying the returns for the EW portfolio that are below the expected return (or the sample average over each period), pairing those returns with the returns of the $\mathrm{L}$ and W Portfolios and calculating the Beta for each portfolio (Calculated as the Covariance between the EW and the L and W Portfolios and dividing the Covariance by the Variance of the EW Portfolio). $\mathrm{B}_{+}$is calculated by identifying the returns for the EW portfolio that are above the expected return (or the sample average over each period), pairing those returns with the returns of the $\mathrm{L}$ and $\mathrm{W}$ Portfolios and calculating the Beta for each portfolio (Calculated as the Covariance between the EW and the L and W Portfolios and dividing the Covariance by the Variance of the EW Portfolio).

Theorectical and empirical research on overreaction and investor decision-making has provoked thought and encouraged debates on how the market works. Hong and Stein (1999) described the price discovery process using two classes of investors (i.e. news watchers and momentum traders), who are boundedly rational and operate with limited information sets. Daniel, K. Hirshleifer, D. and Subrahmanyam, A. (1998) postulated that under- and overreaction to market events can be explained using theories grounded in research on investor psychology; namely, that investors are overconfident about private information and that they fall prey to the self-attribtion bias. Brown, N., Kelsey, D., and Wermers, R. (2007) focus more intently on mutual fund managers (i.e. winner and loser fund managers) and found that mutual fund managers with poor past performance tend to exhibit herding behavior based upon analysts' recommendations (i.e. buy stocks that have positive consensus analysts' recommendations and sell stocks that have negative consensus analysts' recommendations), whereas managers that have outperformed recently are less prone to exhibiting herding behavior. Furthermore, they find that this herding behavior leads to underperformance when compared against investment results with similar risks.

Bloomfield, R., Libby, R., and Nelson, M. (1998) "consider two types of portfolio construction rules for use in testing price reactions to information" (p. 6), which are 'information-based' and 'price-based'. The 'information-based' portfolio construction rules are based upon 'value-relevant' information that is independent of market price and 'price-based' rules that are dependent on whether the price of securities or portfolios have increased or decreased in response to the release of information. Bloomfield et al. (1998) posit that "price-based portfolios will tend to yield larger overreactions or smaller underreactions than information-based portfolios, because the market prices typically include an element of random error that is subsequently reversed" (p. 2). This occurs, according to Bloomfield et al. (1998) because "a high-return (low-return) portfolio will tend to include stocks with positive (negative) random error, and will therefore decline (increase) in value" (pgs. 2-3). Bloomfield et al. (1998) illustrated through experiments ran with the participation of MBA students at Cornell's Johnson Graduate School of Management that when hypothetical market participants make decisions based upon 'price' they tend to exhibit statistically significant underreactation to more reliable information and overreact to less reliable information; however, when hypothetical market participants construct portfolios based upon 'information' they show statistically significant signs of underreaction to reliable information, but do not show evidence of statistically significant overreaction to less reliable information (pgs. 18-19). 
Bloomfield, R. and Hales, J. (2002) designed another set of experiments on a similar group of participants at Cornell's Johnson Graduate School of Management to determine if hypothetical investors are more likely to exhibit signs of overreaction to changes in hypothetical market prices based upon the trends previously experienced in market prices. Bloomfield et al. (2002) find that the experiment's participants had a strong tendency to predict trending (p. 411). Moreover, the participants are twice as likely to overreact to reversals when the previous return sequence exhibits trending behavior then when the sequence exhibits many reversals (Bloomfield et al. 2002, p. 411). Bloomfield et al. (2002) suggested that the results of their experiments seem to suggest that the psychological forces leading the participants to expect 'trending' are more powerful than those that lead them to expect reversals (p. 411).

Bloomfield, R. and Hales, J. (2002) cited Barberis, N., Shleifer, A., and Vishny, R. (1998) in which the author's developed a model of investor sentiment that attempts to model overreaction and underreaction to releases of information in securities' prices. Barberis et al. (1998) models the responses to earnings releases and trends in other, more general, market events and suggested that their model accounts for underreaction to informational releases that have high statistical weight / low strength and overreact to informational releases, such as a series of positive earnings releases, which have low statistical weight / high strength. The suggestive undertones in this message seems to suggest that the market's response to events that they categorized as 'extreme', but have relatively little direct impact on the firm, may result in overreaction in terms of price response and events that they categorize as highly relevant to the firm, but are less sensational may lead to underreaction. Since the current study is focused on examining the reversals in trends, the portion of Barberis et al. (1998) that is relevant to consider in this study is the market's response to 'extreme' events that have low statistical weight and might be seen as highly visible or impactful; in this case, the researcher deems an 'extreme' and visible event as an ETF or sector that generates the worst performance in the previous day. Barberies et al. (1998) somewhat sensationalizes this concept by citing the crash of 1987 and the ensuing reversion of prices following the crash, stating that the crash itself (or the change in prices) seemed to provoke the selling and subsequent reversion because there was little fundamental information that would provoke a reversion in pricing ( $\mathrm{p}$. $333)$.

In summary, Bloomfield et al. (1998) illustrated through experimental research that when people make their investment decisions based upon 'price' they tend to underreact to reliable information and overreact to unreliable information and when they make their investment decisions based upon 'information' they underreact to reliable information, but do not overreact to unreliable information. Moreover, Bloomfield et al. (2002) found that people tend to overreact to price changes in a series that exhibit trending behavior; meaning that they overreact to reversals in a series that exhibits trending behavior when compared against a series that seems to be generated by a random process. To test whether the results found in this study support the experimental evidence found in Bloomfield et al. (1998) and Bloomfield et al. (2002) the researcher will first run a test to determine if there is statistically significant differences in average returns from the two groups conditioned on a previously negative performance event (e.g. Bloomfield et al. 1998) and then the researcher will test whether there is statistically significant evidence of non-randomness in the sequence of returns by conducting a runs test (e.g. Bloomfield et al. 2002).

The first test that the researcher will carry out is a test to determine whether there is statistically significant evidence of outperformance conditioned upon a negative performance event. The hypothesis test has been constructed as follows:

$$
\begin{aligned}
& H_{0}: \widehat{r}_{L}>\widehat{r_{M}} \\
& H_{1}: \widehat{r}_{L} \leq \widehat{r_{M}}
\end{aligned}
$$

The hypothesis test was carried out using the following formula:

$$
t_{S T A T}=\frac{\widehat{r_{L}-r_{M}}}{\sqrt{\frac{s_{L}^{2}}{n_{L}}+\frac{s_{M}^{2}}{n_{M}}}}, \text { where }
$$

$\widehat{r_{L}}$ : Is the sample average daily return on the 'Loser Portfolio' conditioned upon a previously negative performance event

$\widehat{r_{M}}$ : Is the sample average daily return on the 'Market Portfolio' conditioned upon a previously negative performance event

$s_{L}$ : Is the sample average daily standard deviation on the 'Loser Portfolio' conditioned upon a previously negative performance event

$s_{M}$ : Is the sample average daily standard deviation on the 'Market Portfolio' conditioned upon a previously negative performance event 
$n_{L}$ : Is the number of sample observations that the 'Loser Portfolio's' experienced a negative performance event $n_{M}$ : Is the number of sample observations that the 'Market Portfolio's' experienced a negative performance event.

For this analysis the researcher examined all of the time series returns for each of the ETFs in one group and all of the returns of the 'Loser' Portfolio's returns in another group. The following filter was run: if $\left(r_{t-1}<0, r_{t}, 0\right)$. This filter provides the researcher with all of the returns of both groups conditioned on the previous return being less than zero. The returns of the 'Market Group' produced an average daily return of $0.035 \%$ and an average daily standard deviation of $1.183 \%$ with 11,908 observations and the 'Loser Portfolio' group produced an average daily return of $0.099 \%$ and a standard deviation of $1.621 \%$ with 1,356 observations. The researcher conducted a one-tailed $t$-test and generated critical $t$-value of 1.42 , which translates to a $p$-value of $7.78 \%$. Therefore, with a $\alpha$ of .10, the researcher has found statistically significant evidence that the average performance of the 'Loser Portfolio' conditioned on a previously negative performance event was greater than the performance of the 'Market Portfolio'.

To test whether the series is completely random or exhibits signs of nonrandom behavior or 'runs', the researcher conducted a 'runs test'. The test is constructed as follows:

$H_{0}$ : the sequence was produced in a random manner

$H_{1}$ : the sequence was not produced in a random manner

$$
\begin{gathered}
\bar{R}=\frac{2 n_{1} n_{2}}{n_{1} n_{2}}+1 \\
S_{R}^{2}=\frac{2 n_{1} n_{2}\left(2 n_{1} n_{2}-n_{1}-n_{2}\right)}{\left(n_{1}+n_{2}\right)^{2}\left(n_{1}+n_{2}-1\right)} \\
Z=\frac{R-\bar{R}}{s_{R}}
\end{gathered}
$$

The runs test rejects the null hypothesis if the absolute value of $Z$ is outside of the critical boundaries for a two-tailed $Z$ test. For this test, the researcher determined how many times both groups (i.e. the ETFs and the 'Loser Portfolio') produced positive performance. For the 'Market Portfolio' there were 14,525 (i.e. $n_{+}$) positive performance events, 26,433 total events, and the $\overline{R_{M}}$ was 13,088 . For the 'Market Portfolio' the researcher found that there was statistically significant evidence that the sequence was non-random using an $\alpha$ of .001 (Note 2). For the 'Loser Portfolio' there were 1,047 (i.e. $n_{+}$), 2,403 total events, and the $\overline{R_{L}}$ was 1,183 . For the 'Loser Portfolio' the researcher also found statistically significant evidence that the sequence was non-random using an $\alpha$ of .001 (Note 3).

Summarizing the findings, the researcher has illustrated that there is statistically significant evidence that when losses are experienced or there is negative price performance that the 'Loser Portfolio' outperforms the 'Market Portfolio'. In addition, the return generating sequences of both portfolios are non-random and they both generate sequences that exhibit trending behavior. These findings combined may offer the first cursory evidence generated from market data confirming what Bloomfield et al. (1998) and Bloomfield et al. (2002) found in their experimental research that they conducted with the help of MBA students at Cornell's Johnson Graduate School of Management. In this study, the researcher found statistically significant evidence that: (a) there is evidence of runs in the data of both the market's performance and the performance of the 'loser' portfolio and (b) the 'loser portfolio', the portfolio with the most extreme losses, outperforms the equally weighted 'market portfolio'.

The present study may also help researchers understand what has been described as a flaw in the Fama and French Three-Factor Model. Previous attempts at modeling the behavior of stock market price performance (based upon the results presented in DeBondt and Thaler 1985) seem to focus in on the finding that securities tend to mean revert or display evidence of longer-term autocorrelation (i.e. Lam, K., Liu, T., \& Wong, W. 2010). Based upon the findings presented in Jegadeesh, N. (1989) and De Bondt, W. and Thaler, R. (1985) it seems as though the modeling should be altered to incorporate short-run negative autocorrelation and longer-term positive autocorrelation. Fama, E. and French, K. (1996) stated that their three-factor model could not explain the results presented Jegadeesh and Titman (1993) who concluded that there is short-term persistence in the performance of individual securities. According to Fama and French, K. (1996) their three-factor model predicts that short-term past winners (losers) load negatively (positively) on HML and their model predicts a reversal in future trends and not a continuation, which fits with the findings presented in this study. 


\section{Conclusion}

The goal of this paper was to document empirical evidence of the 'Loser' and 'Winner' Hypothesis, presented by DeBondt and Thaler (1985) and reexamined in Jegadeesh and Titman (1993) using a unique data set and multiple examination periods. DeBondt et al. identified statistically significant outperformance of the Loser Portfolio over the Winner Portfolio using portfolios of individual securities rebalanced at the beginning of each year from 1933 to 1980. Constructing the portfolios in this way exposed their analysis to potential 'turn of the year' and 'seasonality effects'. This paper uses a different level of analysis (i.e. Sector ETFs versus Individual Securities) and a different rebalancing procedure (i.e. daily versus annually) to avoid these and other potential biases.

The results of this research project illustrate that there is evidence of statistically significant short-run autocorrelation in the performance of the ETFs selected as broad market proxies for this analysis. The results seem to provide supporting evidence to the 'overreaction hypothesis' presented in DeBondt and Thaler (1985). The researcher took additional steps to evaluate whether this overreaction could be explained by stating that the strategy invests in securities that have higher 'systematic' risks and, therefore, on a risk adjusted basis the argument that people overreact to market events is unwarranted. This argument does not seem to hold, given that the risk adjusted performance of the 'Loser Portfolio' had a higher beta ratio (i.e. Upside Beta divided by Downside Beta) across the three different examination periods and over the entire sample.

The theoretical implications of this study are grounded on the experimental research conducted by Bloomfield et al. (1998) and Bloomfield et al. (2002). This study finds significant evidence of trends in both the market portfolio and the loser portfolio (i.e. sign tests were conducted and the results were significant using an $\alpha$ of .001); moreover, the loser portfolio shows signs of significant outperformance when the preceding day's performance is negative (i.e. the researcher found that the average returns for the loser portfolios were greater than the market portfolio using an $\alpha$ of .10). The findings presented in this study offer the first market evidence that specifically supports the experimental findings presented in Bloomfield et al. (1998) and Bloomfield et al. (2002).

In summary, this paper finds statistically and economically significant evidence that a strategy of investing in the 'Loser Portfolio' produced a CAR of $113.50 \%$ over the 'Equally Weighted Portfolio' and the 'Winner Portfolio' produced a CAR of $-134.13 \%$ over that same benchmark from October 1, 2004 to April 17, 2014 using Sector ETFs as proxies for market performance and a daily rebalance. By using a daily rebalance and sector ETFs the researcher minimized the 'seasonality' and 'turn of the year' effects. Furthermore, this project calculated the upside and downside betas of the strategies as well as the ETFs against an Equally Weighted Portfolio to serve as proxies for levels of systematic risks embedded in these strategies. The results presented in previous sections illustrate that the systematic risk embedded in these strategies do not seem to directly explain their abnormal performance. The short-term negative autocorrelation found in this analysis seems to support the overreaction hypothesis, according to DeBondt and Thaler (1985), "that most people 'overreact' to unexpected and dramatic news events" and that this overreaction is rapidly accounted for in the marketplace (i.e. the overreaction leads to a correction and evidence of this correction is short-term negative autocorrelation). Moreover, these findings seem to be grounded in experimental research conducted by Bloomfield et al. (1998) and Bloomfield et al. (2002).

\section{References}

Ang, A., Chen, J., \& Xing, Y. (2006). Downside Risk. The Review of Financial Studies, 19(4), 1191-1239. http://dx.doi.org/10.1093/rfs/hhj035

Barber, B. M., \& Lyon, J. D. (1997). Detecting long-run abnormal stock returns: The empirical power and specification of test statistics. Journal of Financial Economics, 43, 341-372. http://dx.doi.org/10.1016/S0304-405X(96)00890-2

Barberis, N., Shleifer, A., \& Vishny, R. (1998). A model of investor sentiment. Journal of Financial Economics, 49, 307-343. http://dx.doi.org/10.1016/S0304-405X(98)00027-0

Bloomfield, R., Libby, R., \& Nelson, M. (1998). Underreactions and Overreactions: The Influence of Information Reliability and Portfolio Formation Rules. http://dx.doi.org/10.2139/ssrn.132168

Bloomfield, R., \& Hales, J. (2002). Predicting the next step of a random walk: Experimental evidence of regime-shifting beliefs. Journal of Financial Economics, 65, 397-414. http://dx.doi.org/10.1016/S0304-405X(02)00147-2

Brown, Nerissa C., Wei, Kelsey D., \& Wermers, Russ. (2007). Analyst recommendations, mutual fund herding, and overreaction in stock prices, CFR Working Paper, No. 07-08 
Campbell, J. Lo, A., \& MacKinlay, A. (1997). The Econometrics of Financial Markets. Princeton University Press: Princeton, NJ.

Daniel, K., Hirshleifer, D., \& Subrahmanyam, A. (1998). Investor Psychology and Security Market Under- and Overreactions. The Journal of Finance, 53(6), 1839-1885. http://dx.doi.org/10.1111/0022-1082.00077

De Bondt, W. F. M., \& Thaler, R. (1985). Does the Stock Market Overreact? The Journal of Finance, 40(3), 793-805. http://dx.doi.org/10.1111/j.1540-6261.1985.tb05004.x

Fama, E., \& French, K. (1996). Multifactor Explanations of Asset Pricing Anomalies. The Journal of Finance, 51(1), 55-84. http://dx.doi.org/10.1111/j.1540-6261.1996.tb05202.x

Faramarzi, M., Ketabi, S., \& Zare, R. (2013). The investigation of overreaction and the effect of the short-term investment periods. Global Business and Economics Research Journal, 2(5), 42-54.

Hong, H., \& Stein, J. (1999). A unifed theory of underreaction, momentum trading, and overreaction in asset markets. The Journal of Finance, 54(6), 2143-2184. http://dx.doi.org/10.1111/0022-1082.00184

Jegadeesh, N. (1990). Evidence of PredicTable Behavior of Security Returns. The Journal of Finance, 45(3), 881-898. http://dx.doi.org/10.1111/j.1540-6261.1990.tb05110.x

Jegadeesh, N., \& Titman, S. (1993). Returns to Buying Winners and Selling Losers: Implications for Stock Market Efficiency. The Journal of Finance, 48(1), 65-91. http://dx.doi.org/10.1111/j.1540-6261.1993.tb04702.x

Lam, Kin, Taisheng Liu, \& Wing Keung Wong. (2010). A pseudo-Bayesian model in financial decision making with implications to market volatility, under- and overreaction. European Journal of Operational Research, 203(1), 166-175. http://dx.doi.org/10.1016/j.ejor.2009.07.005

\section{Notes}

Note 1. Faramarzi, M., Ketabi, S., and Zare, R. (2013) found no evidence of the 'winner' / 'loser' effect in their examination of 152 companies' performance in the Tehran stock exchange.

Note 2. The critical value of $t$ was 17.85

Note 3 . The critical value of $t$ was -5.63 